\title{
Risk Perceptions of Environmental Hazards and Human Reproduction: A Community-Based Survey
}

\author{
Ashley Shepherd, ${ }^{1}$ Ruth Jepson, ${ }^{2}$ Andrew Watterson, ${ }^{3}$ and Josie M. M. Evans ${ }^{4}$ \\ ${ }^{1}$ School of Nursing, Midwifery and Health, University of Stirling, Stirling, FK9 4LA, UK \\ ${ }^{2}$ Centre for Public Health and Population Health Research, University of Stirling, Stirling, FK9 4LA, UK \\ ${ }^{3}$ Occupational and Environmental Health Research Group, University of Stirling, Stirling, FK9 4LA, UK \\ ${ }^{4}$ Epidemiology Research Programme, Centre for Public Health and Population Health Research, University of Stirling, \\ Stirling, FK9 4LA, UK
}

Correspondence should be addressed to Ashley Shepherd, ashley.shepherd@stir.ac.uk

Received 2 September 2011; Accepted 25 September 2011

Academic Editor: M. Zmyslony

Copyright (C) 2012 Ashley Shepherd et al. This is an open access article distributed under the Creative Commons Attribution License, which permits unrestricted use, distribution, and reproduction in any medium, provided the original work is properly cited.

\begin{abstract}
Objectives. We have investigated the Australian public's perceived risks on human reproductive health from a number of identified environmental hazards. Methods. A sample of 1261 subjects was interviewed. This interview included specific questions related to perceived risks of certain environmental hazards to human reproductive health. Results. Women were almost twice as likely to rank all hazards as harmful or very harmful to human reproduction than men. Age also influenced perceived risk with those in the 35 and older age groups more likely to rank lead as a harmful hazard when compared with the 18-34 group. Pesticides were identified by $84.5 \%$ of the sample as the most harmful environmental hazard to human reproduction. Conclusions. Similar to other environmental hazards, different groups of people in the general population perceive hazards relating to reproductive health differently. This information is important for both policy makers and health professionals dealing with reproductive environmental health issues.
\end{abstract}

\section{Introduction}

Environmental health is an area of growing concern due to major global environmental changes and an increase in established links between a number of diseases and environmental exposures. Children and the developing fetus are known to be particularly vulnerable to the impact of environmental pollution [1] and as such, the European Environment Agency (EEA) [2] and the World Health Organisation (WHO) [3] have highlighted this as a high priority which warrants further research.

Established risks for the fetus that relate to life circumstances and so-called lifestyle factors include smoking and second hand smoke, alcohol and other licit and nonlicit drugs, and physical exercise linked to factors such as obesity $[4,5]$. These might be viewed as "social environmental risk factors" where data are often extensive and research has been conducted in some instances for decades. Greater uncertainty and doubt exist about what could be described as nonpersonal environmental risk factors and their impacts generated not by choices but by activities external to and usually beyond the control of individuals. These are the focus of our paper. They may also often involve complex interactions and long-term, low-level exposures and reviews flag both the established risks and new potential hazards during pregnancy that may involve a range of environmental factors.

The effects of exposure to environmental toxins especially for pregnant women were propelled into the public domain in the 1960s with events such as the poisoning of Minamata Bay by mercury dumped by a plastics company [6]. Infants born to mothers who had consumed contaminated fish from the bay developed a number of problems including cerebral palsy, developmental delays, central nervous system damage, and blindness.

Environmental health hazards affecting human health are most commonly classified as chemical, biological, physical, mechanical, and psychological. These can be naturally occur- 
ring hazards (e.g., radon in drinking water) or constructed (e.g., pesticides on food) [7]. Although exposure to chemicals at critical periods of susceptibility in utero may result in lifelong adverse health effects, the effects of many of these environmental toxins to the developing fetus are unknown [7]. Pregnant women are exposed to environmental factors such as air pollution, pesticides, domestic and commercial chemicals, and radiation through their place of work, their home, or their local environment. In 2005, a number of reports relating to exposure of babies to contaminants through cord blood provoked further interest in the link between environmental exposure and child health $[8,9]$. A recent survey in the United States concluded that virtually all pregnant women carry multiple chemicals within their bodies. Interestingly, some of these detected chemicals have been banned since the early 1970s and others are used commonly in personal care products or nonstick cookware [10].

A number of systematic reviews (literature reviews using systematic, transparent, and reproducible methods) have examined the evidence on the associations between prenatal exposure to environment hazards and adverse effects on children (see Table 1). There is evidence that parental exposure to pesticides is associated with cancer in children $[11,13$, 14] particularly childhood leukaemia [13, 14]. Exposure to pesticides is also linked to several other cancers, birth defects, fetal death, and altered growth $[9,12]$. Exposure to polychlorinated biphenyls (PCBs) can have a subtle effect on children's neurodevelopment [19], and lead and PCBs can affect brain development, behaviour, and reproduction at very low levels [30]. There is also evidence to suggest a causal relationship between air pollution and fetal growth but the association is small and it is difficult to determine which particulates are most harmful [15-18]. However, there is equivocal or conflicting evidence on the associations between effects on the fetus and diagnostic X-rays [31], nonionizing radiation $[20,21]$, exposure to hair products [26], and nitrates in drinking water [24].

The public perceptions and attitudes towards risk and risk reduction are central to the "new" public health [32]. There is an increasing emphasis on both public health and health promotion bodies to avert risks of disease, particularly in high risk populations or where large populations may be exposed. Risk discourse in public health can be separated into various perspectives including: risk to health as a result of individual lifestyle choices and environmental hazards such as pollution and toxic chemicals [33]. Beck first used the term "risk society" in the 1990s [34] and he viewed risk as a product of late modernity, whereby human progress and human development have produced more and more hazards which threaten the ecosystem and human health. His statements about risk mainly focus on external hazards and dangers (e.g., pollution and global warming). For Beck, modern society changed fundamentally from a society characterised primarily by social inequalities (such as income) to a society where (although such inequalities remain) the chief threats are environmental hazards which cut across traditional inequalities. He specifically identified the different responses of the scientific community and the public to risk and observed: "scientific rationality without social rationality is empty: social reality without scientific rationality is blind." $\mathrm{He}$ further noted that: "Social movements raise questions that are not answered by the risk technicians at all, and the technicians answer questions which miss out what was really asked and what feeds public anxiety" [34].

Whilst it is commonly accepted that dangers and hazards do exist, they are not necessarily viewed equally by the public. However the public's concerns about risks cannot necessarily be attributed to ignorance or irrationality. It has been maintained that risk has generally been discussed through a "paradigm of rational choice" and to consider risk assessment independent of culture is useless [35]. Research has also shown that much of the public's reactions to risk can be attributed to how they respond to hazards in terms of technical, social, and perceptional elements that are not normally well addressed in risk assessments [36].

There is relatively little research on the general public's perceptions of specific environmental factors related to reproductive health $[37,38]$. These reviews and recent guides in the USA $[39,40]$ concur that this is an area of considerable significance to public health although it is underresearched. Australia is a country of special interest because in some areas it has progressive laws in the field in question, it contains a wide range of potentially interesting reproductive environmental hazards, and it has a number of national surveys that explore environmental attitudes. Queensland contains agricultural, mining, industrial activities, and a range of urban and rural settings. The state has also some progressive social legislation.

The aim of this study was to explore aspects of the public's perceived risks of environmental hazards on human reproduction by (i) gender, (ii) place of residence (city, town or rural), (iii) age, and (iv) presence of children in the household. The specific environmental hazards considered in this study were selected due to the previous work we have conducted in this area and from the literature reviewed. These are also the hazards that are believed to be most familiar to the public.

\section{Materials and Methods}

The study employed survey methods of a randomly selected sample of people living in Australia. The study received ethical approval from the University Human Research Ethics Committee. Data were collected in July and August 2010 as part of the annual Queensland Social Survey conducted by the Population Research Laboratory at Central Queensland University. Sampling was a two-stage selection process involving (i) selection of households; (ii) selection of respondent within each household. The target population designated for telephone interviewing was all persons of 18 years of age or older who, at the time of the survey, were living in a home in Queensland that could be contacted by direct dialing to a land-based telephone service. A random selection approach was used to ensure that all respondents had an equal chance to be contacted. The sampling error is a measure of the validity of the descriptive statistics that are observed in a sample. Survey estimates of sampling error for 
TABLE 1: Summary of review level evidence on associations between exposure and outcomes in pregnancy.

\begin{tabular}{|c|c|c|c|}
\hline Potential hazard & Outcome investigated & Evidence base & $\begin{array}{l}\text { Association between exposure } \\
\text { and outcome* }\end{array}$ \\
\hline Pesticides & Childhood cancer & Systematic review $^{1}[11]$ & + \\
\hline Pesticides & $\begin{array}{l}\text { Reproductive effects: birth } \\
\text { defects, fetal death, altered } \\
\text { growth, and other outcomes. }\end{array}$ & Systematic review [12] & + \\
\hline $\begin{array}{l}\text { Residual pesticides, insecticides } \\
\text { and herbicides }\end{array}$ & Childhood leukaemia & Systematic review [13] & + \\
\hline Pesticides (parental exposure to) & Childhood leukaemia & Systematic review [14] & + \\
\hline Air pollution & Fetal growth & Systematic review [15] & + \\
\hline Air pollution & $\begin{array}{l}\text { Fetal growth } \\
\text { Respiratory deaths }\end{array}$ & Systematic review [16] & \pm \\
\hline Air pollution & $\begin{array}{l}\text { Fetal growth } \\
\text { Duration of pregnancy }\end{array}$ & Systematic review [17] & \pm \\
\hline Air pollution & $\begin{array}{l}\text { Fetal growth and duration of } \\
\text { pregnancy }\end{array}$ & Systematic review [18] & \pm \\
\hline $\begin{array}{l}\text { Polychlorinated biphenyls } \\
\text { (PCBs) }\end{array}$ & Child neurodevelopment & Systematic review [19] & + \\
\hline $\begin{array}{l}\text { Electromagnetic fields } \\
\text { (nonionizing radiation) }\end{array}$ & Childhood leukaemia & Systematic review [20] & \pm \\
\hline Low level radio-frequency & $\begin{array}{l}\text { Birth defects, fertility, } \\
\text { neuroblastoma in offspring, \& } \\
\text { reproductive hormones }\end{array}$ & Literature review [21] & \pm \\
\hline Parental smoking & Childhood cancer & Systematic review [22] & + \\
\hline $\begin{array}{l}\text { Working in floriculture (exposed } \\
\text { to, physical activity, temperatures } \\
\text { \& pesticides) }\end{array}$ & $\begin{array}{l}\text { Spontaneous abortion and birth } \\
\text { defects }\end{array}$ & Meta-analysis of two studies [23] & + \\
\hline Nitrates in drinking water & $\begin{array}{l}\text { Spontaneous abortions, } \\
\text { intrauterine growth restriction, } \\
\text { and various birth defects }\end{array}$ & Literature review [24] & \pm \\
\hline Agent Orange (dioxin) & Birth defects & Systematic review [25] & + \\
\hline $\begin{array}{l}\text { Working in } \\
\text { hairdressers-exposure to hair } \\
\text { products }\end{array}$ & $\begin{array}{l}\text { Fertility and pregnancy } \\
\text { complications } \\
\text { Birth malformations particularly } \\
\text { orofacial cleft }\end{array}$ & Systematic review [26] & \pm \\
\hline Diagnostic X-rays & Childhood cancer & Systematic review [27] & \pm \\
\hline Tritium & Various & Systematic review [28] & \pm \\
\hline Environmental oestrogens & Male reproductive health & Systematic review [29] & \pm \\
\hline $\begin{array}{l}\text { Lead, polychlorinated biphenyls, } \\
\text { mercury, cocaine, alcohol, } \\
\text { marijuana, cigarettes and } \\
\text { antidepressants. }\end{array}$ & $\begin{array}{l}\text { Mental health in children and } \\
\text { adolescents }\end{array}$ & Systematic review [30] & $\begin{array}{l}+ \text { for some exposure } \\
\quad \pm \text { for others }\end{array}$ \\
\hline
\end{tabular}

${ }^{1}$ A systematic review uses systematic, reproducible, and transparent methods to identify, appraise, and synthesise studies.

${ }^{*+}$ association between exposure to hazard and outcome.

${ }^{ \pm}$conflicting or not enough evidence of an association between exposure to hazard and outcome.

- No association between exposure to hazard and outcome.

the total sample of 1261 indicate that this is accurate within plus or minus 2.7 percentage points, at a $95 \%$ confidence interval [41].

The sample was drawn using list-assisted random digit dialling. All duplicate and mobile telephone numbers were removed from the generated lists. A respondent within each household was preselected on the basis of gender to ensure an equal yet random selection of male and female participants. Within the household, one eligible person was selected as the respondent for the 30-minute interview. A respondent within each household was selected on the basis of gender using the following selection guidelines to ensure an equal yet random selection of male and female participants: (i) the dwelling unit must be the person's usual place of residence, and he/she must be 18 years of age or older; (ii) each household was randomly preselected as either a male or female household; (iii) if there was more than one male/female in the household then the male/female that 
had the most recent birthday was selected; (iv) If there was no-one of the preselected gender residing in the house then the house was designated not qualified. Past surveys have indicated that $60 \%$ of the time, the first household contact is female. Previous experience indicated that recruitment to the survey was more successful when calls were made in the evenings or weekends.

The questionnaire was pilot-tested by trained interviewers on a total of 52 respondents. Interviewer comments (e.g., any confusing questions, inadequate response categories etc.) and pretest response distributions were made available to the researchers. Following this pilot, one of our questions' response categories was modified for the main data collection.

The Queensland Social Survey is an annual omnibus survey that addresses a variety of topics of interest to the research community. The survey consists of a standardised introduction, a series of question sets reflecting the specific research interests of the university and community researchers participating in the study, and demographic questions. Questions relating to the public's opinion of environmental hazards and human reproduction were embedded into the survey. Interviewees were asked to firstly rank five individual environmental hazards from "very harmful" to not "harmful at all" to human reproduction and secondly to choose from a list of five hazards which they perceived to be the hazard most harmful to human reproduction. Selection of the questions on common reproductive hazards in the survey were geared to covering some of the most common hazards linked to reproduction and likely to occur in the state and based on the knowledge of the authors of those substances or activities linked to environmental exposure in major international and national governmental and scientific guides [38].

All data were cleaned, coded and analysed using PASW Statistics Version 18. The data-cleaning process included wild code, discrepant value, and consistency checks. Simple frequencies were calculated for each question and expressed as percentages. Frequencies were presented by total sample, gender, age group, place of residence, and presence of children in the household. The resultant data set contains 1261 cases.

For questions where respondents were asked as to whether they considered a list of potential environmental hazards to be very harmful, harmful, neutral, slightly harmful, or not harmful at all to reproduction, numbers and percentages of those considering them to be harmful or very harmful were determined and stratified by gender, age group, place of residence, and presence of children in the household. A logistic regression was then carried out with whether or not the pollutant was considered to be harmful or very harmful as the dependent variable. Odds ratios were determined for each covariate, adjusted for all other covariates.

\section{Results}

There were 1261 telephone interviews completed and the characteristics of the respondents are presented in Table 2. Comparison of the survey sample with the most recent
Australian Bureau of Statistics (ABS) census data (2006) revealed there was oversampling in the 45-65+ age categories and under sampling in the under 45 age categories. The response rate was calculated by dividing the number of people participating in the survey (completed or partially completed interview) by the number of people in the selected survey. For this survey the response rate was $35.2 \%$.

In the total sample of Queensland residents, there was general agreement that pesticides, household chemicals, and animal-borne diseases had either a very harmful or harmful effect on human reproduction (Table 2). Pesticides were described by the highest proportion $(84.5 \%)$ of the sample as harmful or very harmful. This agreement ranged from a low of $70.5 \%$ in the $18-34$-year-old age group to a high of $88 \%$ in the $45-54$-year-old age group. With only $26.3 \%$ of the sample ranking cosmetics and hair colours as harmful or very harmful, this hazard was perceived to cause the lowest risk to reproduction.

Table 3 represents the result of a logistic regression analyses for each potential hazard. Results indicate that there was a significant association between gender and perceived risk. In general, women were around twice as likely to rank all hazards as harmful or very harmful than men. Those in the 35-44, 45-54, 55-64, and 65 years and older age groups were also all significantly more likely to rank pesticides as harmful or very harmful than those in the 18-34 age group; while those in the 45-54 age group were significantly more likely to rank household chemicals/paints and radiation as harmful or very harmful than the 18-34 age group.

Lead was identified by $48.5 \%$ of respondents to be the most harmful hazard to reproduction when compared with stress $(32.4 \%)$, carrying and lifting $(2.1 \%)$, water pollution $(5.7 \%)$, and air pollution (6.3\%) (Table 4). A Chi-squared test for independence indicated no significant association between most harmful hazard identified with either gender, place of residence or children in the household $(P>0.05)$. A significant association was, however, noted with age $(P<$ $0.001)$. Only $32.5 \%$ of those in the younger age group (18-34 years) identified lead as the most harmful hazard compared with $45.9 \%$ in the $35-44$ group, $52.9 \%$ in the $45-54$ group, $54.4 \%$ in the $55-64$ group, and $49.2 \%$ in the 65 years and older group. Stress, however, was chosen as the most harmful hazard in the younger age group with this agreement decreasing as age increased.

\section{Discussion}

This study provides a snapshot of risk perceptions. Whilst the scientific evidence of the effects of prenatal exposure to environment hazards and adverse effects on children is on the rise, it is important to investigate what the public believe about the exposure to a range of hazards and reproductive health. To date, little empirical data about the public's knowledge about environmental hazards and reproduction have been reported. Data such as that collected in this study has been compared with the scientific evidence base, whether that provides strong, weak, or absent links to adverse effects to human health. Comparisons such as these may provide an 
TABLE 2: Percentages of sample who ranked each hazard as harmful or very harmful to human reproduction.

\begin{tabular}{|c|c|c|c|c|c|c|}
\hline & $(\%)$ & (\%) & $\begin{array}{l}\text { Household } \\
\text { chemicals \& } \\
\text { paints } \\
(\%)\end{array}$ & $\begin{array}{c}\text { Radiation (e.g., } \\
\text { pylons, microwaves, } \\
\text { and phone masts) } \\
(\%)\end{array}$ & $\begin{array}{c}\text { Cosmetics and } \\
\text { hair colours } \\
(\%)\end{array}$ & $\begin{array}{c}\text { Animal-borne } \\
\text { diseases } \\
\%\end{array}$ \\
\hline Total sample $(n=1261)$ & - & 84.5 & 68.8 & 53.4 & 26.3 & 62.5 \\
\hline \multicolumn{7}{|l|}{ Gender $(n=1261)$} \\
\hline Male & 50.4 & 80.0 & 60.0 & 48.2 & 28.8 & 53.4 \\
\hline Female & 49.6 & 89.1 & 77.8 & 58.6 & 31.9 & 71.7 \\
\hline \multicolumn{7}{|l|}{ Age group $(n=1251)$} \\
\hline $18-34$ & 13.2 & 70.5 & 60.2 & 45.8 & 20.5 & 63.3 \\
\hline $35-44$ & 17.3 & 87.6 & 73.4 & 54.1 & 26.6 & 62.4 \\
\hline $45-54$ & 23.1 & 88.0 & 71.1 & 57.0 & 27.1 & 65.3 \\
\hline $55-64$ & 22.4 & 87.6 & 72.4 & 57.6 & 30.4 & 64.3 \\
\hline $65+$ & 24.0 & 83.8 & 64.7 & 49.5 & 24.8 & 57.8 \\
\hline \multicolumn{7}{|l|}{$\begin{array}{l}\text { Place of residence } \\
(n=1257)\end{array}$} \\
\hline City & 52.0 & 84.1 & 68.4 & 51.2 & 25.2 & 62.5 \\
\hline Town & 25.5 & 84.1 & 68.8 & 53.3 & 27.7 & 63.2 \\
\hline Rural & 22.2 & 86.1 & 69.6 & 58.6 & 27.9 & 62.1 \\
\hline \multicolumn{7}{|l|}{$\begin{array}{l}\text { Children in the household } \\
(n=1258)\end{array}$} \\
\hline No & 64.6 & 83.4 & 68.2 & 53.8 & 27.3 & 62.2 \\
\hline Yes & 35.2 & 86.7 & 70.3 & 52.7 & 24.5 & 63.3 \\
\hline
\end{tabular}

Note. No response given to age $n=10(0.8 \%)$, place or residence $n=4(0.3 \%)$, and children in the household $n=3(0.2 \%)$.

invaluable contribution to both environmental health policy and practice developments.

Setting the results either in the context of Australia as a whole, or globally, is difficult because of the lack of comparative studies using similar methodologies. However, the Australian-wide survey of public environmental health perceptions, not specifically environmental risk to human reproduction, based on 2,008 interviews and carried out in 2000 did identify some similar but broad brush conclusions to our study, both on gender responses and several hazards. It commented that concerns about risks that affected children and pregnant women are usually heightened and noted: "Pollution issues all frequently rated as high risks, with chemical pollution overall being regarded as the greatest risk. Chemicals such as pesticides and insecticides were considered high risk by about half of respondents. Dioxin chemicals ranked lower however, perhaps indicating a lack of recognition of this class of chemicals. New or topical issues such as food irradiation and genetically modified food did not rank as high a risk as most of the other categories" [42, page 31].

A pioneering study which is still relevant to the present analysis of global risks to health concluded that the most highly uncertain risks such as pesticides and nuclear power are deemed the most dreaded, while risks associated with health interventions and clinical procedures are more acceptable [43]. A range of factors have been shown to influence risk perceptions and these are embedded within different economic, social, and cultural environments [44]. Some of these have been explored in the survey such as gender, age, and location. Others like employment, family and peer group, and education may also be factors. The media too plays a part in risk perception and rating - the web as well as radio, TV, and newspapers are of growing significance although evidence-based media sources may not always be accessed.

We conducted a search, using environmental health, reproduction, and specific hazard topics of all national Australian and major Western Australian newspapers through the Nexis-Lexis newspaper database for the three months prior to the survey date. We also accessed the websites of major Australian TV channels for the same period using the same search terms. Surprisingly, no major stories on general environmental hazards linked to reproductive outcomes were identified. Major TV channels such as ABC had only one story on the topic in the six months prior to the survey. In the early 2000s, there had been several major news stories linked to pesticides and reproduction, other more general stories on environmental hazards not specifically related to reproduction, such as female breast cancer clusters in TV offices, that may have shaped some public responses to hazard ratings. These sources have often diverse and complex influences that merit further investigation but are beyond the scope of the current survey.

Where different generations had some extensive sensitisation to or greater knowledge of hazards than later generations, risk ratings, whatever the evidence base indicates, may be lower or may be higher for a range of reasons. 
TABLE 3: Adjusted odds ratios and 95\% confidence intervals for associations between sociodemographic variables and whether respondents considered hazards to be harmful or very harmful to reproduction.

\begin{tabular}{|c|c|c|c|c|c|c|}
\hline & Sample & Pesticides & $\begin{array}{c}\text { Household } \\
\text { chemicals and } \\
\text { paints }\end{array}$ & $\begin{array}{l}\text { Radiation (e.g., } \\
\text { pylons, microwaves, } \\
\text { phone masts) }\end{array}$ & $\begin{array}{l}\text { Cosmetics and } \\
\text { hair colours }\end{array}$ & $\begin{array}{c}\text { Animal borne } \\
\text { diseases }\end{array}$ \\
\hline & $(\%)$ & $\operatorname{AOR}(95 \% \mathrm{CI})$ & AOR $(95 \% \mathrm{CI})$ & AOR (95\% CI) & $\operatorname{AOR}(95 \% \mathrm{CI})$ & $\operatorname{AOR}(95 \% \mathrm{CI})$ \\
\hline \multicolumn{7}{|c|}{ Gender $(n=1261)$} \\
\hline Male & 50.4 & 1.00 Ref & 1.00 Ref & 1.00 Ref & 1.00 Ref & 1.00 Ref \\
\hline Female & 49.6 & $\begin{array}{c}2.04 \\
(1.48-2.83)^{*}\end{array}$ & $\begin{array}{c}2.32 \\
(1.81-2.98)^{*}\end{array}$ & $1.52(1.22-1.90)^{*}$ & $\begin{array}{c}1.78 \\
(1.38-2.30)^{*}\end{array}$ & $\begin{array}{c}2.25 \\
(1.78-2.85)^{*}\end{array}$ \\
\hline \multicolumn{7}{|c|}{ Age group $(n=1251)$} \\
\hline $18-34$ & 13.2 & 1.00 Ref & 1.00 Ref & 1.00 Ref & 1.00 Ref & 1.00 Ref \\
\hline $35-44$ & 17.3 & $\begin{array}{c}2.44 \\
(1.41-4.21)^{*}\end{array}$ & $\begin{array}{c}1.67 \\
(1.06-2.61)^{*}\end{array}$ & $1.36(0.89-2.07)$ & $1.40(0.85-2.30)$ & $0.88(0.57-1.37)$ \\
\hline $45-54$ & 23.1 & $\begin{array}{c}3.27 \\
(1.98-5.41)^{*}\end{array}$ & $\begin{array}{c}1.65 \\
(1.09-2.49)^{*}\end{array}$ & $1.53(1.04-2.27)^{*}$ & $1.41(0.88-2.25)$ & $1.07(0.71-1.61)$ \\
\hline $55-64$ & 22.4 & $\begin{array}{c}3.71 \\
(2.19-6.31)^{*}\end{array}$ & $1.79(1.15-2.78)$ & $1.54(1.01-2.33)^{*}$ & $1.59(0.97-2.59)$ & $1.01(0.66-1.56)$ \\
\hline $65+$ & 24.0 & $\begin{array}{c}2.80 \\
(1.69-4.64)^{*}\end{array}$ & $1.25(0.81-1.93)$ & $1.11(0.73-1.68)$ & $1.19(0.72-1.96)$ & $0.77(0.50-1.18)$ \\
\hline \multicolumn{7}{|c|}{$\begin{array}{l}\text { Place of residence } \\
(n=1257)\end{array}$} \\
\hline City & 52.0 & 1.00 Ref & 1.00 Ref & 1.00 Ref & 1.00 Ref & 1.00 Ref \\
\hline Town & 25.5 & $1.06(0.72-1.54)$ & $1.01(0.75-1.36)$ & $1.09(0.83-1.43)$ & $1.15(0.85-1.56)$ & $0.98(0.74-1.30)$ \\
\hline Rural & 22.2 & $1.11(0.74-1.68)$ & $1.06(0.77-1.44)$ & $1.34(1.01-1.78)^{*}$ & $1.15(0.84-1.58)$ & $0.99(0.74-1.33)$ \\
\hline \multicolumn{7}{|c|}{$\begin{array}{l}\text { Children in the household } \\
(n=1258)\end{array}$} \\
\hline No & 64.6 & 1.00 Ref & 1.00 Ref & 1.00 Ref & 1.00 Ref & 1.00 Ref \\
\hline Yes & 35.2 & $\begin{array}{c}1.71 \\
(1.13-2.59)^{*} \\
\end{array}$ & $1.11(0.81-1.54)$ & $0.96(0.71-1.29)$ & $0.89(0.63-1.26)$ & $1.02(0.75-1.40)$ \\
\hline
\end{tabular}

Note. each odds ratio is adjusted for all other variables in the table; no response given to age $n=10(0.8 \%)$, place or residence $n=4(0.3 \%)$, and children in the household $n=3(0.2 \%) ;{ }^{*} P<0.05$.

TABLE 4: Response frequencies for hazards respondents perceived as most harmful to human reproduction for either men or women.

\begin{tabular}{|c|c|c|c|c|c|c|}
\hline & $\begin{array}{c}\text { Lead } \\
(\%)\end{array}$ & $\begin{array}{c}\text { Stress } \\
(\%)\end{array}$ & $\begin{array}{l}\text { Carrying and lifting } \\
(\%)\end{array}$ & $\begin{array}{l}\text { Water pollution } \\
\qquad \%)\end{array}$ & $\begin{array}{l}\text { Air pollution } \\
(\%)\end{array}$ & $\begin{array}{c}\text { Don't know/No response } \\
\%\end{array}$ \\
\hline Total sample $(n=1261)$ & 48.5 & 32.4 & 2.1 & 5.7 & 6.3 & 5.0 \\
\hline \multicolumn{7}{|l|}{ Gender $(n=1261)$} \\
\hline Male & 46.5 & 33.4 & 2.4 & 5.5 & 6.6 & 5.7 \\
\hline Female & 50.5 & 31.5 & 1.9 & 5.9 & 5.9 & 4.3 \\
\hline \multicolumn{7}{|l|}{ Age group $(n=1251)$} \\
\hline $18-34$ & 32.5 & 43.4 & 3.0 & 10.2 & 7.8 & 3.0 \\
\hline $35-44$ & 45.9 & 40.4 & 0.9 & 2.8 & 5.5 & 4.6 \\
\hline $45-54$ & 52.9 & 32.0 & 1.7 & 5.5 & 3.4 & 4.5 \\
\hline $55-64$ & 54.4 & 27.6 & 1.4 & 4.6 & 7.8 & 4.2 \\
\hline $65+$ & 49.2 & 25.7 & 3.6 & 6.6 & 7.3 & 7.6 \\
\hline \multicolumn{7}{|c|}{ Place of residence $(n=1257)$} \\
\hline City & 50.6 & 29.0 & 2.6 & 6.4 & 6.6 & 4.9 \\
\hline Town & 43.6 & 36.1 & 1.2 & 5.6 & 6.2 & 7.1 \\
\hline Rural & 49.6 & 35.7 & 1.8 & 4.3 & 5.7 & 2.9 \\
\hline \multicolumn{7}{|c|}{ Children in the household $(n=1258)$} \\
\hline No & 48.9 & 30.1 & 2.5 & 5.9 & 7.2 & 5.4 \\
\hline Yes & 47.5 & 36.9 & 1.6 & 5.4 & 4.5 & 4.1 \\
\hline
\end{tabular}

Note. No response given to age $n=10(0.8 \%)$, place or residence $n=4(0.3 \%)$, and children in the household $n=3(0.2 \%)$. 
Hazards widely publicised over several decades such as pesticides in general and specific pesticides in particular appear to score highly. However, older hazards that are considered to be no longer present at levels or in places that might threaten health may sometimes be given lower risk ratings. The risk rating may be further lowered if up-todate scientific evidence is not available or not highlighted in the population at large. Lead is a case in point in Table 4 [45]. City dwellers were more likely to rate lead as the most harmful hazard to human reproduction when compared with town dwellers ( $50.6 \%$ versus $43.6 \%$ ). This may again reflect particular concerns about lead paint in old buildings and in pipes with related information campaigns and public health interventions to remove the hazard in large conurbations.

The chronic high-level exposures to lead have been well known and well publicised as have the effects of high exposures on female reproduction whilst the male reproductive health hazards of lead have been downplayed or ignored. However, recent research has focused on effects that are chronic, low level, and sometimes subtle including reproductive effects. The neurological and behavioural as well as the reproductive effects of very low lead levels in humans have yet to percolate through into the public domain. This raises a raft of questions about information, communication, regulation, and enforcement on environmental hazards.

Familiarity that is sometimes a reflection of knowledge and sometimes of ignorance may also explain some low ratings, and lack of knowledge of a hazard may explain high-risk ratings. For example, in Table 2 similar rankings surprisingly exist from residents in cities and towns for animal-borne diseases to that of residents in rural areas. This may be because those working with animals in agricultural areas come across zoonotic diseases frequently and rate the risks highly, whereas those in towns and cities hear about a few dangerous zoonotic diseases and may overestimate their threats. Alternatively, dog- and cat-borne diseases may be brought to the attention of owners by vets and are more widely publicized than other hazards in urban areas particularly in terms of toxocaria canis and toxoplasmosis. There is some evidence too that vets and physicians assess and identify zoonotic threats differently: vets may downplay tick-borne diseases as they are not involved in human diagnoses, and physicians may misunderstand the threats of toxoplasmosis from sheep [46]. With such confusion among health professionals, it is unsurprising that there may be confusion in the minds of the public about what are real threats and what the scale of those threats is?

The responses for animal-borne diseases again show a greater risk perception for women than men although a zoonotic-specific set of questions might have elicited different responses. Hence there is much information publicly available about reproductive adverse effects in women from zoonotic diseases that men and women would be aware of. Risks of contracting Q disease are probably more limited to those in abattoirs and animal husbandry. The age profiles on risk perceptions, however, are harder to interpret with age group 45-54 ranking risks higher and the 18-34 group ranking risks lowest. This may reflect the knowledge and experience base of responders.

There is a growing body of evidence to indicate that women express far greater concern than men with regard to health and environmental hazards [47]. Explanations for this difference have focused on both social and biological factors. It has been suggested by some that there is an association between knowledge of the potential hazard and the perceived risk [47]. However, in a study of male and female scientists of similar scientific training [48], the authors concluded that male scientists tended to see substantially less risk from nuclear technologies and materials than female scientists. A review of 85 published studies in this area [49] reported that for 38 studies that examined nuclear power and radio-active waste, women expressed greater concern in every study; for the 19 studies that examined risk-related environmental issues such as toxic chemical waste, women expressed greater concern in $95 \%$ of these.

Men ranked stress, air pollution, and lifting and carrying as greater hazards to reproduction than women (Table 4). Why this should be so is not clear. Air pollution and lifting and carrying have not been linked to adverse male reproductive effects and it may be that women adjust to everyday hazards that they face and "downplay" them. With much recent information and media discussion of stress, it is perhaps easier to explain why younger age groups rank stress highest and older age groups place it lowest although different definitions of stress may be used by different age groups. Findings for which no explanation exist or where sample size may be a factor occur on water pollution which attracts the highest hazard rating for younger age groups but the lowest for the 35-44 group.

Although insightful, the current study was subject to a number of limitations. Participants were volunteers and therefore there may be some selection bias. However, it is worth noting that respondents were answering questions on a number of health-related topics and are unlikely to have agreed to participate because they feel strongly about the topic area being studied here. Also, only Queensland residents that were contactable by a landline telephone were able to participate. It should be acknowledged that the sample is not representative of the Australian population with over representation of the 45 years and older age group and under representation of the 45 years and younger group. Gaining adequate participation of younger respondents when conducting computer-assisted telephone interviewing surveys using only randomly generated landline telephone samples has become more difficult as increasing numbers of young people use only mobile telephones. Recent studies have shown that exclusion of mobile-phone-only households does not significantly influence survey results [50]. The response rate of $35.2 \%$ is representative of general household surveys which have been on the decline in recent years [51]. It has been suggested that with reduced telephone number listings and people's increasing resistance to unwanted phone calls, alternatives to telephone surveys, such as computer and internet-based approaches, should be investigated [52]. Strengths of this study include the use of a large state-wide sample to conduct an analysis of perceived risks of environ- 
mental health on human reproduction. No similar survey of this topic and of this scale has been reported in the scientific literature.

\section{Conflict of Interests}

The authors declare that they have no conflict of interests.

\section{Acknowledgments}

The authors thank all those from the Central Queensland Social Survey for collection of data and the School of Nursing, Midwifery and Health, University of Stirling for funding this study.

\section{References}

[1] R. R. Dietert, "Developmental immunotoxicology: focus on health risks," Chemical Research in Toxicology, vol. 22, no. 1, pp. 17-23, 2009.

[2] European Environment Agency, Environment and Health, European Environment Agency, Copenhagen, Denmark, 2005.

[3] WHO Regional Office for Europe, Children's Environment and Health Action Plan for Europe, www.euro.who.int/data/assets/pdf_file/0006/78639/E83338.pdf 2004 (last accessed 04/2011).

[4] D. T. Wigle, T. E. Arbuckle, M. C. Turner et al., "Epidemiologic evidence of relationships between reproductive and child health outcomes and environmental chemical contaminants," Journal of Toxicology and Environmental Health-Part B: Critical Reviews, vol. 11, no. 5-6, pp. 373-517, 2008.

[5] A. M. N. Andersen and J. Olsen, "The Danish national birth cohort: selected scientific contributions within perinatal epidemiology and future perspectives," Scandinavian Journal of Public Health, vol. 39, supplement 7, pp. 115-120, 2011.

[6] T. Takeuchi, N. Morikawa, H. Matsumoto, and Y. Shiraishi, "A pathological study of Minamata disease in Japan," Acta Neuropathologica, vol. 2, no. 1, pp. 40-57, 1962.

[7] S. Chalupka, "Environmental health: an opportunity for health promotion and disease prevention," American Association of Occupational Health Nurses, vol. 53, no. 1, pp. 13-28, 2005.

[8] J. Houlihan, T. Kropp, R. Wiles, S. Gray, and C. Campbell, Body Burden: The Pollution in Newborns, Environmental Working Group, Washington, DC, USA, 2005.

[9] G. Lyons and A. A. Watterson, Review of the Role Pesticides Play in Some Cancers: Children, Farmers and Pesticide Users at Risk?. www.chemtrust.org.uk 2010 (last accessed 04/2011).

[10] P. Sutton, L. C. Giudice, and T. J. Woodruff, "Reproductive environmental health," Current Opinion in Obstetrics and Gynecology, vol. 22, no. 6, pp. 517-524, 2010.

[11] K. L. Bassil, C. Vakil, M. Sanborn, D. C. Cole, J. S. Kaur, and K. J. Kerr, "Cancer health effects of pesticides: systematic review," Canadian Family Physician, vol. 53, no. 10, pp. 1705-1711, 2007.

[12] M. Sanborn, K. J. Kerr, L. H. Sanin, D. C. Cole, K. L. Bassil, and C. Vakil, "Non-cancer health effects of pesticides: systematic review and implications for family doctors," Canadian Family Physician, vol. 53, no. 10, pp. 1712-1720, 2007.

[13] M. C. Turner, D. T. Wigle, and D. Krewski, "Residential pesticides and childhood leukemia: a systematic review and meta- analysis," Environmental Health Perspectives, vol. 118, no. 1, pp. 33-41, 2010.

[14] G. van Maele-Fabry, A. C. Lantin, P. Hoet, and D. Lison, "Childhood leukaemia and parental occupational exposure to pesticides: a systematic review and meta-analysis," Cancer Causes and Control, vol. 21, no. 6, pp. 787-809, 2010.

[15] M. Maisonet, A. Correa, D. Misra, and J. J. Jaakkola, "A review of the literature on the effects of ambient air pollution on fetal growth," Environmental Research, vol. 95, no. 1, pp. 106-115, 2004.

[16] R. J. Sram, B. Binkova, J. Dejmek, and M. Bobak, "Ambient air pollution and pregnancy outcomes: a review of the literature," Environmental Health Perspectives, vol. 113, no. 4, pp. 375-382, 2005.

[17] S. V. Glinianaia, J. Rankin, R. Bell, T. Pless-Mulloli, and D. Howel, "Particulate air pollution and fetal health: a systematic review of the epidemiologic evidence," Epidemiology, vol. 15, no. 1, pp. 36-45, 2004.

[18] I. Annesi-Maesano, U. Ackermann, C. Boudet et al., "Health effects of atmospheric particles: review of the epidemiologic studies," Environnement, Risques et Sante, vol. 3, no. 2, pp. 97110, 2004.

[19] N. Ribas-Fitó, M. Sala, M. Kogevinas, and J. Sunyer, "Polychlorinated biphenyls (PCBs) and neurological development in children: a systematic review," Journal of Epidemiology and Community Health, vol. 55, no. 8, pp. 537-546, 2001.

[20] I. Calvente, M. F. Fernandez, J. Villalba, N. Olea, and M. I. Nuñez, "Exposure to electromagnetic fields (non-ionizing radiation) and its relationship with childhood leukemia: a systematic review," Science of the Total Environment, vol. 408, no. 16, pp. 3062-3069, 2010.

[21] J. R. Jauchem, "Effects of low-level radio-frequency $(3 \mathrm{kHz}$ to $300 \mathrm{GHz}$ ) energy on human cardiovascular, reproductive, immune, and other systems: a review of the recent literature," International Journal of Hygiene and Environmental Health, vol. 211, no. 1-2, pp. 1-29, 2008.

[22] J. F. I. Tortajada, J. A. O. García, J. A. L. Andreu, O. B. Tornero, A. M. Macián, and J. G. I. Castell, "Parental tobacco smoke and childhood cancer," Revista Espanola de Pediatria, vol. 60, no. 3, pp. 225-236, 2004.

[23] A. J. Idrovo and L. H. Sanin, "Adverse reproductive outcomes among women working in colombian floriculture: a summary of the evidence through meta-analysis," Biomedica, vol. 27, no. 4, pp. 490-497, 2007.

[24] D. M. Manassaram, L. C. Backer, and D. M. Moll, "A review of nitrates in drinking water: maternal exposure and adverse reproductive and developmental outcomes," Environmental Health Perspectives, vol. 114, no. 3, pp. 320-327, 2006.

[25] A. D. Ngo, R. Taylor, C. L. Roberts, and T. V. Nguyen, "Association between agent orange and birth defects: systematic review and meta-analysis," International Journal of Epidemiology, vol. 35, no. 5, pp. 1220-1230, 2006.

[26] C. Peters, M. Harling, M. Dulon, A. Schablon, J. T. Costa, and A. Nienhaus, "Fertility disorders and pregnancy complications in hairdressers - a systematic review," Journal of Occupational Medicine and Toxicology, vol. 5, no. 24, 2010.

[27] A. Schultze-Mosgau, G. Griesinger, C. Altgassen, S. von Otte, D. Hornung, and K. Diedrich, "New developments in the use of peptide gonadotropin-releasing hormone antagonists versus agonists," Expert Opinion on Investigational Drugs, vol. 14, no. 9, pp. 1085-1097, 2005.

[28] M. P. Little and R. Wakeford, "Systematic review of epidemiological studies of exposure to tritium," Journal of Radiological Protection, vol. 28, no. 1, pp. 9-32, 2008. 
[29] A. C. Vidaeff and L. E. Sever, "In utero exposure to environmental estrogens and male reproductive health: a systematic review of biological and epidemiologic evidence," Reproductive Toxicology, vol. 20, no. 1, pp. 5-20, 2005.

[30] J. H. G. Williams and L. Ross, "Consequences of prenatal toxin exposure for mental health in children and adolescents: a systematic review," European Child and Adolescent Psychiatry, vol. 16, no. 4, pp. 243-253, 2007.

[31] R. Schulze-Rath, G. P. Hammer, and M. Blettner, "Are pre- or postnatal diagnostic X-rays a risk factor for childhood cancer? a systematic review," Radiation and Environmental Biophysics, vol. 47, no. 3, pp. 301-312, 2008.

[32] A. Petersen and D. Lupton, The New Public Health. Health and Self in the Age of Risk, Sage, Washington, DC, USA, 1996.

[33] D. Lupton, The Imperative of Health. Public Health and the Regulated Body, Sage, Washington, DC, USA, 1995.

[34] U. Beck, Risk Society: Towards a New Modernity, Sage, Washington, DC, USA, 1992.

[35] M. Douglas, Risk and Blame: Essays in Cultural Theory, Rou$\backslash$ linebreak teledge, London, UK, 1992.

[36] P. Slovic, "Public perception of risk," Journal of Environmental Health, vol. 59, pp. 22-23, 1997.

[37] H. A. Grason and D. P. Misra, "Reducing exposure to environmental toxicants before birth: moving from risk perception to risk reduction," Public Health Reports, vol. 124, no. 5, pp. 629$641,2009$.

[38] A. Watterson, P. Thomson, C. Malcolm, A. Shepherd, and C. McIntosh, "Integrating environmental health into nursing and midwifery practice," Journal of Advanced Nursing, vol. 49, no. 6, pp. 665-674, 2005.

[39] R. Etzel and S. J. Balk, Eds., Pediatric Environmental Health, 2nd edition, 2003.

[40] D. G. Shendell and A. Pike-Paris, "Environmental exposure assessment, pollution sources, and exposure agents: a primer for pediatric nursing professionals," Pediatric Nursing, vol. 33, no. 2, pp. 179-182, 2007.

[41] E. Babbie, The Practice of Social Research, International Thomson, London, UK, 1989.

[42] G. Starr, A. Langley, and A. Taylor, Environmental Health Risk Perception in Australia : A Research Report to the Commonwealth Department of Health and Aged Care, Department of Human Services, Adelaide, Australia, 2000.

[43] P. Solvic, B. Fischhoff, and S. Lichtenstein, "Facts and fears: undertanding perceived risk," in Societal Risk Assessment: How Safe Is Safe Enough? R. C. Schwing and W. A. Albers, Eds., pp. 181-214, Plenum, New York, NY, USA, 1980.

[44] World Health Organisation, World Health Report 2002. Perceiving Risks, chapter 3, World Health Organisation, City, State, USA, 2003.

[45] R. O’Neil, Dangerous Lead. http://www.hazards.org/lead/ 2009 (last accessed 04/2011).

[46] W. A. Crofting, Health and the Environment Report, Stirling University, Scotland, UK, 2010.

[47] D. C. Kovacs, M. J. Small, C. I. Davidson, and B. Fischhoff, "Behavioral factors affecting exposure potential for household cleaning products," Journal of Exposure Analysis and Environmental Epidemiology, vol. 7, no. 4, pp. 505-520, 1997.

[48] R. P. Barke, H. Jenkins-Smith, and P. Slovic, "Risk perceptions of men and women scientists," Social Science Quarterly, vol. 78, no. 1, pp. 167-176, 1997.

[49] D. J. Davidson and W. R. Freudenburg, "Gender and environmental risk concerns: a review and analysis of available research," Environment and Behavior, vol. 28, no. 3, pp. 302339, 1996.
[50] D. W. Pennay and N. Bishop, Profiling the "Mobile Phone Only" Population: A Study of Australians with a Mobile Phone and No Landline Telephone, Social Research Centre Pty Ltd, Melbourne, Australia, 2009.

[51] R. Curtin, S. Presser, and E. Singer, "Changes in telephone survey nonresponse over the past quarter century," Public Opinion Quarterly, vol. 69, no. 1, pp. 87-98, 2005.

[52] J. O'Toole, M. Sinclair, and K. Leder, "Maximising response rates in household telephone surveys," BMC Medical Research Methodology, vol. 8, no. 71, 2008. 


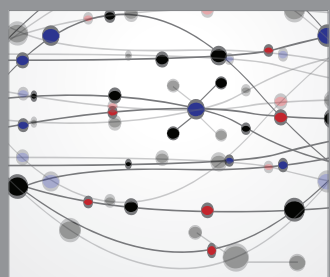

The Scientific World Journal
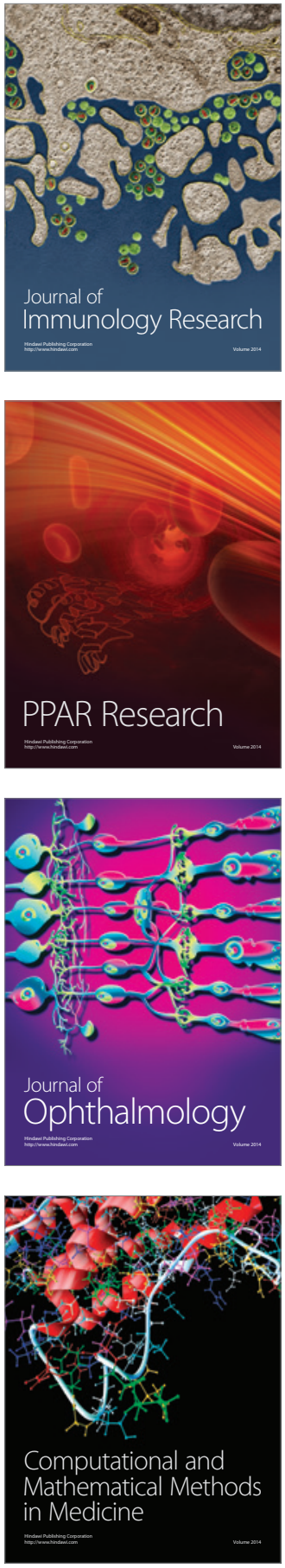

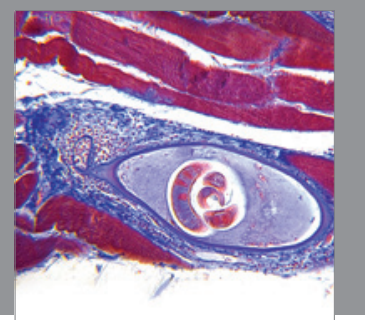

Gastroenterology

Research and Practice
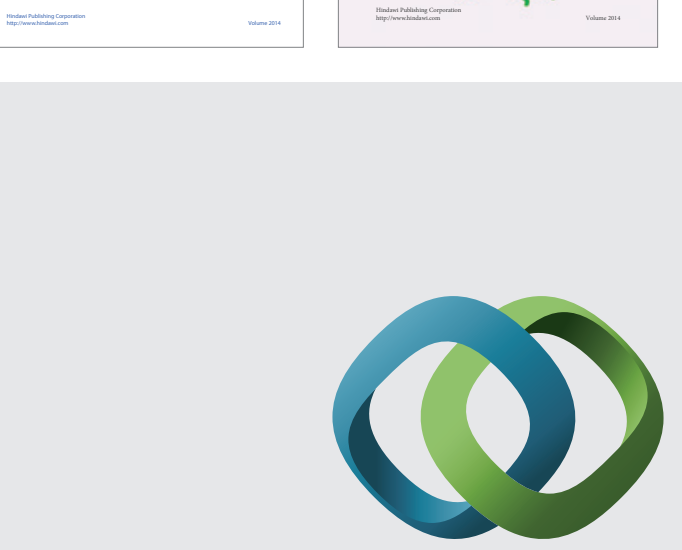

\section{Hindawi}

Submit your manuscripts at

http://www.hindawi.com
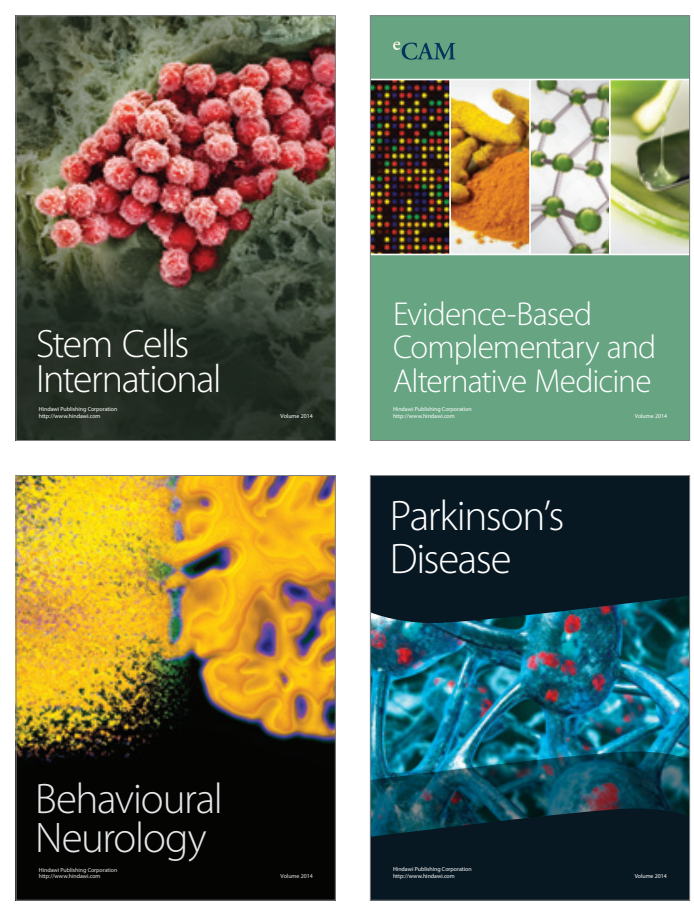

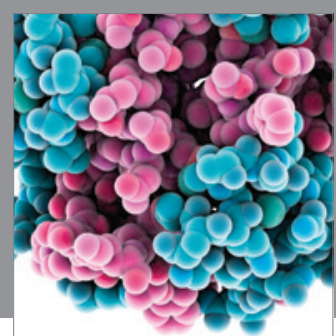

Journal of
Diabetes Research

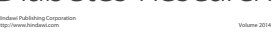

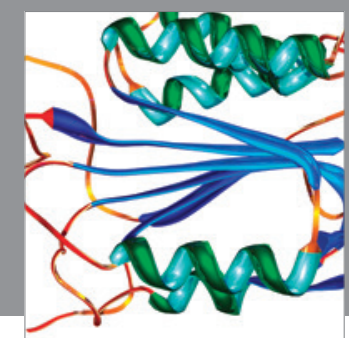

Disease Markers
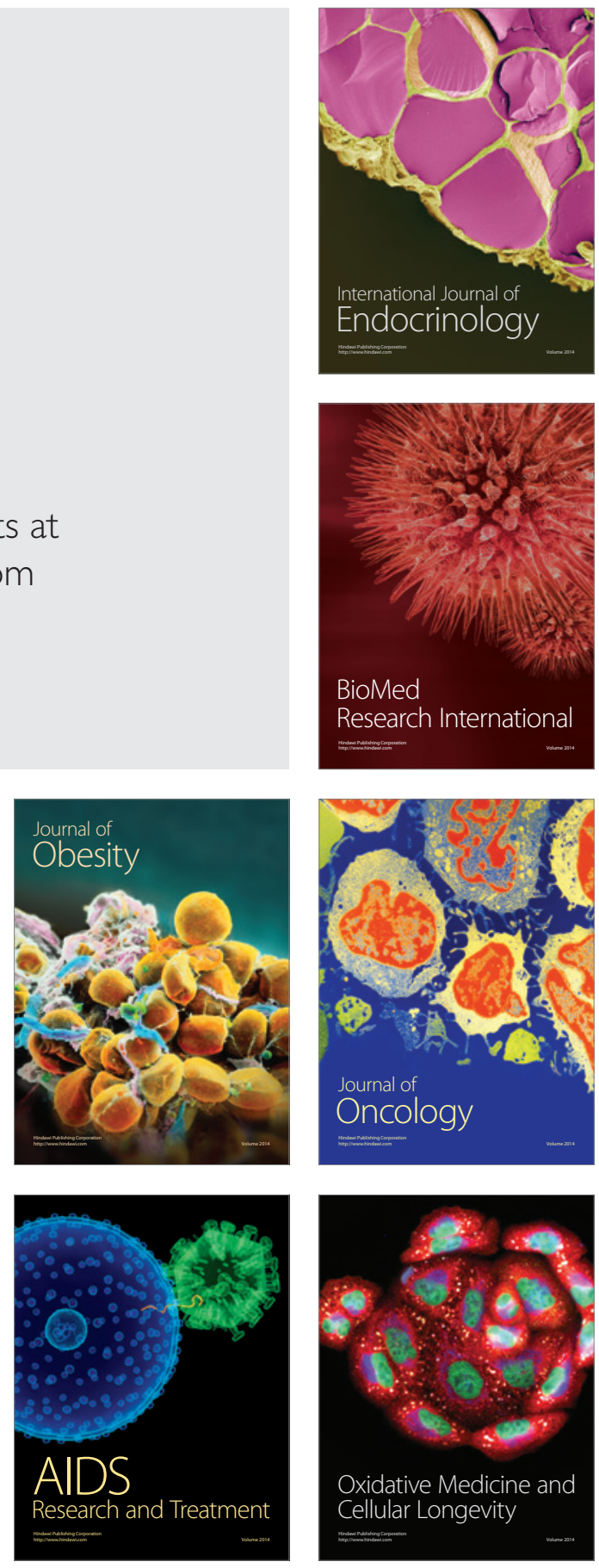